\title{
1 Introduction to The Structure of Regulation
}

Our relationship to the environment is under scrutiny. The situation is said to be more pressing than at any time in the past, with daily reminders of the damage inflicted. Climate change, plastics in oceans, biodiversity loss, and premature deaths from air pollution, come readily to mind. In response, all but a minority demand that action is taken, expecting answers and solutions to what can be complex problems. Any failure to deliver, however, is not the result of the number of laws in place. For instance, a recent report from the United Nations Environment Programme pointed to a 38-fold increase in laws since $1972 .{ }^{1}$ The report went on to attribute failure to weak enforcement rather than the laws themselves, and while this is important, we will argue that the structure of regulation is equally, if not more, important. Indeed, poorly structured regulation will hinder compliance even when enforcement is adequate, and, for that reason, the question we must ask concerns how regulation can be best configured to deliver compliance. It is the question that is the focus of our work.

To understand our own thoughts on regulation, and how these thoughts have evolved, we need to go back to the year 2000. It was the starting point of a period when we visited firms, mainly on industrial estates in and around North Staffordshire. The visits were interesting and at times eye-opening, with several memorable incidents including one where we were removed from the premises under the suspicion of being undercover officers! Thankfully, and more generally, the people were very welcoming. It was evident in how they talked candidly on issues to do with complaints from neighbours, supply chain pressures, and even noncompliance. The firms tended to be small or micro in size (i.e., they had fewer than 50 or fewer than 10 employees, respectively) and they frequently considered themselves to be lean, having removed all unnecessary costs to remain as competitive as possible. Typically, they felt their impacts on the environment were negligible and they had little need to improve their environmental performance. This did not necessarily mean they had no interest or concern for environmental issues, although it was clear that

1 United Nations Environment Programme, Environmental Rule of Law: First Global Report (January 2019). 
some did not. Rather, for many firms, environmental issues had been pushed to the margins owing to commercial pressures.

In trying to make sense of what was observed, we looked carefully to identify consistencies and patterns in the behaviour of firms. Our observations turned out to be largely in line with the work of others. The data showed that smaller firms had a desire, first and foremost, to be compliant and to do no more than what is prescribed in law. The owners and managers we interviewed would often say that a basic level of compliance would safeguard their ability to operate as a commercial entity, which was of utmost importance. Compliance, they said, also enabled them to sleep at night! Other points included the belief that regulations worked best when they were easy to access, when they were easy to understand, and when they could be implemented at minimum cost. In equal measure, they felt that regulations needed to be properly enforced, not least to stop the problem of free-riding by other firms. This was mirrored by a lack of faith in softer approaches such as guidance and support. They considered them ineffective as they would be ignored by many firms.

Over time, and as we gathered more data, it became apparent that the issues were far more complex than we had originally believed. We started to see that there were different characteristics across firms and that these were more profound than previously envisaged. These differences existed along multiple lines: from small firms to large firms, from poor to rich, from low to advanced technology, and so forth. In addition, these differences were associated with different compliance behaviours. This led us to develop a set of compliance archetypes.

\section{ARCHETYPES, COMPLIANCE INTERACTIONS, AND THE STRUCTURE OF REGULATION}

The compliance archetypes emerged from an investigation into the way small and large firms responded to regulation. ${ }^{2}$ In line with previous studies, the analysis found that larger firms tended to have more awareness of, and were more responsive to, environmental issues than smaller firms. Not only did larger firms have more resources and expertise, but it was also likely that they experienced greater institutional pressures and civic scrutiny. This led, in the main, to larger firms taking environmental issues more seriously, and therefore investing more resource to improve their environmental performance. Yet, and this was pivotal, the analysis revealed that both smaller and larger firms also differed among themselves. For example, there were different levels

2 David Williamson and Gary Lynch-Wood, 'Ecological modernisation and the regulation of firms' (2012) 21(6) Environmental Politics 941. 


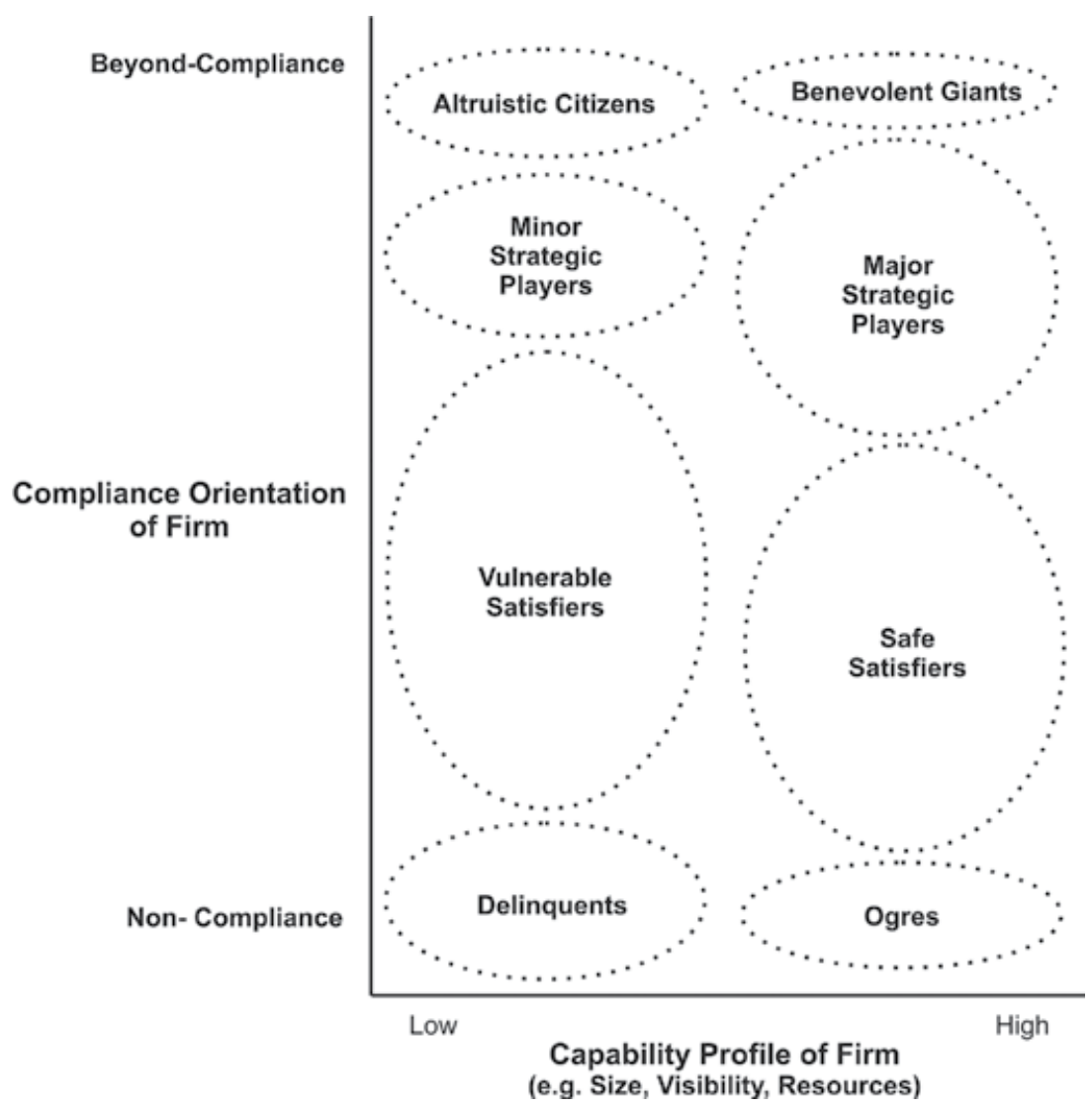

Figure 1.1 Compliance archetypes

of resource and expertise among smaller firms. Some had fewer and more enlightened employees, while others of the same size were less enlightened, and so on. Taking stock of these types of differences led us to identify eight types of firm, which we paired by size (i.e., small and large) and compliance orientation. This is shown in the response archetypes in Figure $1.1,{ }^{3}$ with the pairs being delinquents and ogres, vulnerable satisfiers and safe satisfiers, minor strategic players and major strategic players, and for the final pair, altruistic citizens and benevolent giants.

3 ibid. 


\section{Response Archetypes}

The critical point to the categorisation is that environmental responsiveness increases as you move from delinquents and ogres through to altruistic citizens and benevolent giants. Also, the archetypes were not populated evenly, with the socio-economic environment making some types of behaviour more likely than others. We realised from this that these different archetypes, as constituencies who responded differently to regulation, required different regulatory interventions. Specifically, what was relevant for one type of firm would be less relevant for another type. As a consequence, applying a singular and one-dimensional regulation to all firms would not optimise levels of compliance.

While we still see these archetypes as providing a convenient way of understanding how firms respond to regulation, and providing an advancement of other typologies, they do not provide sufficient insight into why firms interact with regulation as they do. This has led us to investigate, in a more detailed way, the relationship between organisational differences and regulation. There are a number of important and interconnected strands to that investigation. This included asking why firms exhibit different rule following behaviours, why different types of regulations are premised on specific types of rule following, why regulation has inbuilt conditions that firms then have to satisfy, and why firms differ in their endowments of those very same conditions. Crucially, interactions between these different strands explained why there are different levels of compliance and why there is no one-size-fits-all regulatory solution. Rather, the reality is that regulation, of whatever type, involves a trade-off. The trade-off is between the level of certainty of outcome we want from a regulation and the number of firms able to meet that threshold of certainty. To apportion failure of compliance to enforcement, as did the United Nations report, is therefore, at best, only half of the story - it fails to recognise that if you set the level of certainty too high (i.e., the level of stringency) you make compliance impossible for many firms, irrespective of the level of enforcement.

The Structure of Regulation develops these points by providing an explanation of the factors that combine to determine the form of the regulatory problem, and why regulation duly succeeds and fails. It is a structural issue because regulation can be configured with different weightings of these factors, with the weightings interacting with their counterparts in firms to determine the character of the regulation, and in line with this, the character of compliance. The structure of regulation is not, therefore, about a fine-grained analysis of law, about how regulation should be laid out for legal purposes. Rather, it applies to regulation regardless of that type of analysis, or the specific task the regulation is seeking address, or even the type of regulation to be used. And in doing this it addresses previous shortcomings in regulatory 
explanations, which have frequently underplayed or overlooked the structural character of regulation, and accordingly, have underplayed or overlooked how the factors involved work together to determine the shape and performance of regulation. The factors, which will be explained in detail, are embedded in firms and regulation, and have not been brought together as necessary building blocks for a theory of regulation. Instead, the focus, as we will show, has tended to be on issues such as strategies for compliance, including those to do with the use of punishment or persuasion, on the type of regulation to use, such as command and control or market instruments, on how the type of regulation should be escalated, from self-regulation to mandated requirements, and why regulation should be designed and policed based upon notions of risk. In seeking to address the deficit, our analysis develops a compliance line to demonstrate the trade-offs which accompany decisions on how to regulate. The use of a compliance line also enables us to appreciate how regulation can be structured to improve compliance. While the justification behind this will be explained in detail, it involves having both a minimum requirement and an incentive, with the setting of the minimum requirement and the incentive determining the level and type of compliance that we wish to achieve. It is important to point out that this is not a silver bullet, since, as the analysis will show, there is no silver bullet capable of delivering compliance at the levels demanded by many commentators.

Before we get to that point, there is a story that needs to be told. The chapters that follow seek to build upon each other in a way that is coherent, moving from a review of how regulation has changed over the years, and has sought to improve its performance, through to the building of the argument that leads to the identification of the regulation related trade-offs and the provision of a revised framework for how regulation can be structured. We are aware that in presenting this, we have covered some areas in more detail than others. Also, in earlier drafts we included more references, but as we revised the book it became apparent that this impeded the flow of the argument. We therefore decided to keep the references to a minimum, to only retain key or representative sources (apologising if we have offended anyone by doing so).

\section{STRUCTURE OF THE BOOK}

The chapter on regulation sets the scene. It looks at how regulation has changed, with the key theme being the ongoing concern with - and new learning about - how regulation performs. Starting the analysis, we briefly outline early command and control approaches, which are the mainstay of most regulatory regimes, considering what they involve and how they have developed. We also consider some of the criticisms of command and control approaches. Part of the pressure for change has come from theoretical work, including that 
associated with reflexive law, which has led the call for less centralised and hierarchical methods of control. Other influences have arisen from sustainable development policies and ideas positing that market economies, when correctly stimulated, are better suited to providing environmental solutions. The chapter proceeds to consider alternative approaches, such as market-based methods, self-regulatory instruments, and information-based solutions. Each is discussed, with their strengths and weaknesses outlined. Having set out this background, we move on to look at other developments, some driven by theory and others less so. We look at responsive regulation, which has been, and continues to be, highly influential. Responsive regulation advocates a pyramid of regulatory sanctions and a pyramid of regulatory approaches, with escalation up the pyramids if and when the first layer fails to deliver the desired behaviour. We also look at really responsive regulation, which is an extension of responsive regulation. Next, we look at risk-based regulation, which continues to be influential, proceeding from this to look at regulatory reform agendas, where the focus is on making regulation more effective and efficient. Finally, we consider smart regulation, which suggests that the answer to regulatory problems resides in mixes of regulation. In summarising the chapter, we note the ongoing effort to understand, develop and apply more effective forms of regulation. However, there remain longstanding disagreements, highlighting the contested character of existing theories and practices.

The next chapter, on regulation and rule following, provides the first part of an explanation for why firms take different compliance positions. The focus of the chapter is on rule following, on why rule following is the basis for our understanding of the world around us. Central to this is the view that rule following is learnt in the way we live our lives. By looking at rule following, we start to see that firms learn to understand the world differently, and, by extension, to respond differently to regulation. Different rule following practices are demonstrated by looking at the different sentiments we express through the speech that we learn, which are associated with contexts such as social class. Developing this, it is shown that our knowledge of the world, which is constructed by our learning, is a practical ability. Compliance and noncompliance can be part of a learnt activity, being part of the structures that determine the type of learnt activity in which we engage. Since these structures are highly variegated, due to them being affected by multiple factors such as education, we can anticipate that firms exist within a dynamic network of position practices and that this has a significant bearing on compliance. This is demonstrated by looking at the everyday behaviours of firms. The literature on this is extensive, covering as it does the factors that can differentiate one firm from another. What is important is that any similarity between firms is to a degree misleading, hiding the selective alertness that distinguishes decision-making across firms. The substantiation of this comes, in the main, from the work of 
Niklas Luhmann, ${ }^{4}$ as he provides a compelling case for firms and legal systems being self-referencing, which equates to them self-selecting to sustain their identity. One of the implications of this, as Luhmann himself alludes to, is that it is difficult to steer firms through the use of regulation. ${ }^{5}$

Having better understood why firms differ, the second step is to gain a deeper appreciation of why regulation can struggle to accommodate these differences. The chapter on the conditions of regulation does this by distinguishing four critical elements: first, that regulations are embedded with three necessary conditions of regulation, which are knowledge, acceptance and resource; secondly, that firms have levels of knowledge, acceptance and resource, which we refer to as the conditions within firms, and that these will differ to those required by the conditions of regulation; thirdly, that regulations are embedded with a certain type of rule following expectation, which we refer to as the predicates of regulation; and fourthly, that firms have embedded within them a certain type of rule following, which we call the predicates of the firm, and that these will differ to the predicates of regulation. The way these four elements interact, we will show, determines the success and failure of regulation. In practical terms, this means that it is impossible (in all but the most abstract circumstances) to have complete compliance. Consequently, the task is to try to affect the factors that are under the control of the regulator, with the purpose that this will help improve compliance.

We then extend the analysis by providing a revised view of regulation, developing issues raised to present a framework for how to regulate firms. It draws on the previous chapters and commences by showing why responses to regulations are self-sustaining. Since they are self-sustaining, the compliance positions of firms will continue unless there is a correction to that behaviour. To that end, the analysis shows that there are three types of potential intervention. These are to reduce the magnitude of the conditions of regulation, to support the conditions of regulation in firms, and to provide feedback to respond to and correct extant behaviour. A key finding from this is that a correction to the magnitude of the conditions of regulation will involve one or more of four types of trade-off. Importantly, each trade-off has implications for what we want regulation to achieve. Moreover, the trade-offs are unavoidable, a consequence of there being a choice between the level of certainty we wish to have in delivering compliance, the number of firms that we want to be able to achieve compliance, and the level of innovation that we would like to see in the

4 Niklas Luhmann, Social Systems (Stanford University Press 1984, 1995 version translated by John Bednarz).

5 Niklas Luhmann, 'Limits of steering' (1997) 14(1) Theory, Culture \& Society 41. 
delivery of compliance. To see how compliance can be improved, we proceed to outline a methodology for regulating. We call this the minmax methodology.

Having outlined the minmax methodology, we end, as a postscript, by briefly reflecting on the exclusions that result from a regulation having to incorporate trade-offs. This is done by revisiting the compliance archetypes to show how the taking of different minmax positions on that line will affect the performance of regulation for each compliance archetype. By doing this, it is shown that regulation must exclude, to a greater or lesser extent, to function as a regulation (i.e., a regulation must have a requirement, a requirement that acts to exclude firms who cannot satisfy that requirement, or alternatively, you include all firms and exclude the environment on account of there being no requirement), it follows that this must have implications for the rule of law, for the need for law to be applied in a fair and equitable manner. Exclusions, it is argued, make such requirements difficult, if not impossible, and by doing so, can undermine legal validity, which duly undermines what many would argue is a key tenet of the rule of law. To investigate this further we look at criteria that are said to support legal fairness and legal equity. This confirms an incompatibility between what is desired of law and the functioning of law through the application of regulation. It shows that the structure of regulation, irrespective of form, affects the rule of law through exclusions. 